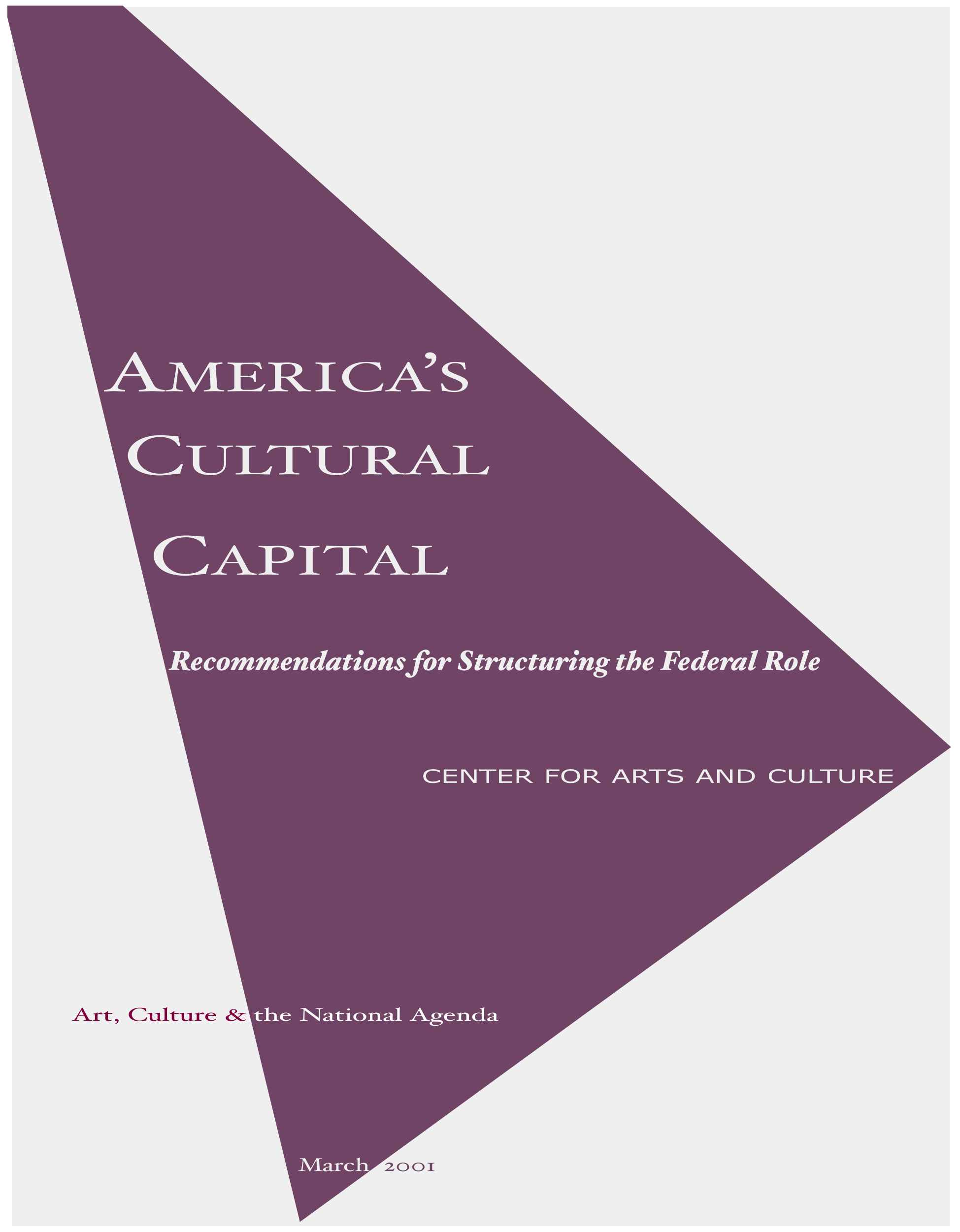




\section{America's Cultural Capital: Recommendations for Structuring the Federal Role}

Culture is a national resource, the accumulated capital of America's ingenuity and creativity. It is the store of human achievement and memory as well as the font of creativity and innovation. Our cultural capital has become increasingly valuable in a global, knowledge-based economy, and as a key social source as people in the United States and around the world seek to preserve their identities and to understand others.

The Center for Arts and Culture strives to foster a national conversation about America's cultural wealth and well-being. During 200I, the Center will be issuing a series of briefing papers that we hope will deepen the discourse about America's artistic creativity, imaginative spirit, cultural life, and the preservation of its cultural heritage. This paper, the first in the series, focuses on four structural recommendations that are intended to improve federal policymaking in these areas. The Center offers these for discussion, debate, and further refinement. We recommend that:

\section{The President establish a mechanism to advise and coordinate cultural affairs in the Executive Office of the President.}

\section{The Department of State establish an Under Secretary for Cultural Affairs.}

\section{Congress develop more comprehensive and integrated approaches to policies affecting cultural affairs.}

\section{Congress and the President create a National Forum on Creativity and Cultural Heritage.}

Policymaking at the federal level relevant to the arts, humanities, and cultural preservation often has been fragmented and fitful. The Center's four proposals aim to create focal points for cultural policies within government that will be better informed, better integrated, and, above all, more suitably aligned with the demands of a global, knowledge-based society. 


\section{The Contributions of the Cultural Sector}

Changes in technology and the global economy compel us to think in new ways about creativity and cultural heritage. Some countries, and now even some states, counties, cities, and towns in the United States, have begun to consider "cultural industries" as a distinctive sector of their economies. Some have begun to analyze the significant contributions that "creative clusters," "creative communities," or the "creative workforce" are now making to domestic productivity, job growth, and export earnings.

Culture's economic contribution is substantial. In the United States, copyright industries, which include film, video, music, publishing, and software, generate nearly $\$ 450$ billion in annual revenues, roughly 5 percent of the Gross Domestic Product. They contribute more than $\$ 79$ billion in global sales. An estimated 7.6 million people now work in these fields, their numbers growing at a rate that has far outpaced job growth in many other economic sectors. The cultural sector, which is a part of the copyright industries, accounts for nearly 2.5 percent of the Gross Domestic Product.

The growing interest in creativity is a response to the relentless pace of innovation in the Information Age. Educators and economists alike are questioning how we can best educate and train a skilled and adaptable workforce for the future.

Creativity and innovation can never be divorced from concerns about preserving and understanding the cultural legacies that nourish and sustain imagination. A superabundance of information moving at lightning speed is not knowledge and will not yield wisdom without criteria for judgment and a habit of reflection. Constant innovation can sever our connections with the past and lead us to neglect our sources of collective memory, values, and identity. Whether historic sites and buildings, collections of documents and books, archives of films and tape, or the skills and techniques of artisans, much of our cultural heritage is now at serious risk of being lost.

In the United States, we are beginning to understand that creativity and cultural heritage can contribute to our well-being in ways that are difficult to evaluate in financial or utilitarian terms. Some policy scholars have begun to develop cultural indicators that help to assess the health of neighborhoods and communities. Foundations have supported programs to draw on the power of the arts and humanities as tools of civic engagement. Scholars concerned with civil society are working to understand how cultural organizations build social capital, by studying the networks and organizations that create and 
sustain a sense of trust, reciprocity, mutual obligation, and engagement.

We can view culture from an economic perspective and thus see creativity and heritage as keys to our continuing success in the new economy. Or we can examine it from a social perspective and see it as the capital that holds communities together and helps them adapt to change. In either case, we must think in new ways about public policies that affect this sector.

\section{Defining Terms}

Although still amorphous and open to continuing redefinition, the concepts of "cultural industries" or a "creative sector" offer important insights into some of the resources that are capable of producing wealth in the new economy as well as sustaining communities in a time of rapid change. These concepts allow us to see relationships that embrace both not-for-profit cultural organizations and commercial firms engaged in publishing, broadcasting, film, recording, the performing arts, the visual arts, and design. We can also begin to discern how varied and interconnected are the forms of participation in artistic and cultural endeavors - singing in amateur choral groups, pursuing genealogical research, attending professional performances, museum exhibits, and classes in a college's extension division, purchasing books and recordings, watching television, or going to the movies. We can see how boundaries shift and blur over time for high culture, popular culture, and mass entertainment. And we can view the arts and humanities not as two isolated collections of artistic and academic disciplines, but as twin parts of a more expansive, interrelated cultural sector.

The cultural sector embraces both creative artists and scholars in the humanities. The sector includes all sorts of institutions and individuals: the galleries and performing arts centers that present and display works; the libraries and archives that preserve our cultural heritage and make scholarly study possible; the not-for-profit and for-profit organizations that determine what is produced and how it is disseminated; the amateur (or unincorporated) organizations through which so many Americans participate in the arts; and those educators at all levels who can engender a love for the arts, an appreciation of the past, and a critical capacity to weigh what is ephemeral, what is worthy, what is meaningful. 


\section{Policy Tools}

The mechanisms that the federal government has used in the cultural arena have provided, for the most part, indirect encouragement and protection of free and competitive markets, and protection of intellectual property and the public interest in it. In the notfor-profit area, tax incentives bolster our traditions of private charitable giving. According to the best estimates, individual donors, foundations, and corporations gave more than \$ro billion to arts, cultural, and humanities organizations in I999.

Annual direct appropriations to federal cultural agencies such as the Smithsonian Institution, Library of Congress, National Archives, Corporation for Public Broadcasting, and the National Endowments for the Arts and the Humanities, among many others, have totaled approximately \$2 billion in recent years. Even as the budgets of some federal cultural agencies were being cut in the r990s, state and local government support was growing substantially. In 1999 state legislatures appropriated about \$400 million in funding for the arts, while local governments spent in excess of $\$ 800$ million. It is far more difficult to measure state and local outlays for the humanities since most of that spending is embedded in budgets for colleges, universities, and library systems.

Ever since the creation of the National Endowment for the Arts and the National Endowment for the Humanities in 1965 , their principal objects of direct concern have been the nation's not-for-profit organizations. The rationale for subsidizing these activities, as is the case with all not-for-profit endeavors, has been that market forces alone, even when bolstered by private philanthropy, cannot preserve what needs to be preserved or assure availability and access to cultural opportunities. In turn, the cultural sector affects education, housing, economic development, and other critical factors in our communities.

While fiscal concerns and the health of not-for-profit arts and humanities institutions will no doubt remain important features of cultural policymaking, we must now begin to address broader and more complicated policy questions. Issues affecting our creative life and cultural heritage arise in trade negotiations, anti-trust enforcement, copyright and patent law decisions, public broadcasting operations, access to the airwaves and common carriers such as the Internet and cable, and our relations with other countries.

Policymaking about the cultural sector is spread widely throughout the government through some 200 programs in at least 30 federal agencies. We must begin to consider 
their interrelationships and to think in more coherent ways about policies affecting this sector. The framework that emerged in the rg6os addressed some of the concerns of that era, but a host of new ones requires more concerted attention.

The Center's briefing papers will explore this new roster of issues. Some of the impending decisions are driven by technological changes; others arise in the context of international trade and diplomacy; still others emerge within local communities and neighborhoods as the nation's demography changes. Our initial issue briefs will be devoted to the following topics:

\author{
Preserving Our Heritage \\ Improving Access to Culture \\ Creativity, Culture, Education, and the Workforce \\ Strengthening American Communities through Culture \\ Globalization and Cultural Diplomacy \\ Sustaining the Investment in Creativity and Culture \\ Intellectual Property in the Information Age
}

Given the clear need for national leadership in this arena, the Center focuses on the federal policymaking framework as a first step. 


\section{RECOMMENDATIONS}

\section{We recommend that the President establish a mechanism to advise and coordinate cultural affairs within the Executive Office of the President.}

\section{Rationale}

The impact of cultural issues far exceeds the policy attention consistently paid to them. While cultural phenomena are sometimes blamed for societal ills, a growing body of research credits them with enhancing the well-being of individuals and communities. Cultural concerns are integral to numerous domestic initiatives and to negotiations with trading partners. The creation and preservation of cultural capital are also affected by decisions such as those that shape copyright law or the telecommunications infrastructure. Culture also has a central role in many efforts to reform schools.

No coherent perspective exists in the more than 200 discrete and often-competing federal programs, both within and outside the agencies traditionally identified with culture. Policies are often created without interagency partnership or consultation, and they receive little or no continuing attention from the Executive Office of the President (EOP). Policies affecting national cultural concerns deserve more than benign neglect or episodic consideration.

\section{Background}

Advisory offices, such as the Council of Economic Advisers, the Office of Science and Technology Policy, and the Council on Environmental Quality, were established in response to a perceived need for Presidential leadership and policy coordination in areas of national importance. Leadership on issues involving the nation's cultural affairs requires the same top-level vigilance and rigorous consideration. The force of the President's bully pulpit depends, at least in part, on such leadership.

In recent decades, several presidents have called upon individuals in the Executive Office 
to function informally as a special assistant for culture. Today, most of our allies and trading partners among the developed nations, as well as many developing countries, appoint high-level officials concerned with the policy implications of cultural issues and, in turn, the cultural implications of broader policy issues. While a Ministry of Culture model will not now or, in all likelihood, ever be suitable for the United States, it is important that as a nation we signal our readiness to approach other countries on equal terms in the cultural arena.

\section{Structure}

The President could accomplish this in a number of ways. He could designate a senior staff member or members to play this advisory role. Cultural issues might be a significant part of the portfolio for individuals appointed to the Domestic Policy Council staff.

The President could take a more substantial step by signing an Executive Order creating an Office of Cultural Affairs within the EOP. The budget and administrative support for this office could come primarily from the EOP, and the office could be staffed with both political appointees and full-time EOP administrative staff. Because the policy concerns of an Office of Cultural Affairs are by nature interagency, relevant agencies would be asked to provide information and assistance as necessary. Regular interagency communication would be significantly improved.

Any cultural advisor would likely interact with the following departments, agencies, and organizations, among others, all of which support programs and make policies that affect our creative life and cultural heritage: the Departments of State, Commerce, Interior, Education, Housing and Urban Development, Agriculture, Health and Human Services, Labor, Defense, Justice, Treasury, Transportation, Energy, and Veterans Affairs; the Smithsonian Institution; National Endowment for the Arts; National Endowment for the Humanities; Institute of Museum and Library Services; National Gallery of Art; Library of Congress; National Archives and Records Administration; National Historic Publications and Records Administration; General Services Administration; Advisory Council on Historic Preservation; Corporation for Public Broadcasting; Office of the U.S. Trade Representative; President's Committee on the Arts and the Humanities; Small Business Administration; Federal Trade Commission; U.S. Patent and Trademark Office; Office of Management and Budget; Environmental Protection Agency; National Science Foundation; and Office of Science and Technology Policy. 
Once an Office of Cultural Affairs has been established, and its value proven, the Administration should then consider incorporating the Office as a more permanent part of the EOP by encouraging Congressional legislation or by including its function within a Government Reorganization Plan.

Centering this mechanism within the EOP would help the President bridge partisan and ideological fissures on specific issues. Moreover, the efforts to preserve our cultural legacies and promote the nation's creative endeavors are national objectives that all Americans can support and that every Administration should pursue over the long term.

\section{We recommend that the Department of State establish an Under Secretary for Cultural Affairs.}

\section{Rationale}

At a time when the global interest in American culture and society is stronger than ever and when our cultural products have become ever more pervasive in world markets, the U.S. government has largely withdrawn from the realm of cultural diplomacy. The amount spent directly by the federal government on international cultural relations has shrunk in real terms from the \$8 million allocated in 1993 to \$I.8 million in 2000.

Given the extraordinary fluidity of global cultural interactions, the opportunities for cultural diplomacy are enormous and unprecedented. The revolution in communications technology and media has given American culture a worldwide reach that often overleaps restrictive policies some governments have used to build walls against it. In many respects, culture has become our most convertible currency. It enables us to reach beyond officialdom to a citizenry increasingly well educated and politically active, especially in parts of the world where authoritarian and totalitarian governments have fallen or are tottering. Indeed, American culture can reach into regions where American military might is seen as threatening, where American commercial activity and investment are regarded with ambivalence, and where American political aims are viewed with suspicion. 
By raising the level at which international cultural relations are discussed, establishing an Under Secretary for Cultural Affairs would yield four important benefits:

I. The cultural sector would be given a defined place at the table where foreign policy is framed.

2. Such a position would provide a focal point for bringing together the 30 government agencies that deal with cultural affairs and place their organizational resources in the service of our foreign policy goals.

3. An Under Secretary for Cultural Affairs would be able to consult with the cultural ministers of other nations. This post would end our official isolation from the group of some 40 countries that now function as an international cultural caucus. Given the increasing importance of trade in cultural products and a lingering disposition among ministers of culture to restrict that trade, the United States needs this representational capacity.

4, Government resources invested in cultural and educational exchanges have proved effective in mobilizing even greater private resources. An Under Secretary for Cultural Affairs could be instrumental in enlisting and coordinating efforts by private groups and individuals in the work of enhancing mutual understanding across borders.

\section{Background}

The retrenchment of cultural diplomacy is not the continuation of a long downward trend; under both the Reagan and George H. Bush administrations cultural programming expanded, and steps were taken to enlarge the role of cultural specialists in such international educational exchanges as the Fulbright program. As part of a broader initiative to strengthen the cultural side of NAFTA, a joint public/private fund was established in Mexico to foster enhanced cultural exchanges, and trilateral academic partnerships were created with the U.S., Canada, and Mexico. In international meetings concerned with cultural properties, the groundwork was laid for more collaboration in protecting cultural patrimony, although those plans were later scrapped. Generally speaking, U.S. cultural relations were expanded in the I980s. 
In Central and Eastern Europe, as the Iron Curtain began to fray, U.S. cultural specialists were sent to a number of countries in the old Soviet Bloc to help rescue major cultural institutions from their fiscal, economic, and administrative disorder. After a long period of decline, the concept of bi-national cultural centers was revived in the hope that these would become more numerous and more active vehicles for cultural contacts. These activities were shaped in the State Department's Bureau of Educational and Cultural Affairs. While there was strong competition for resources from the public information, press, and broadcasting operations of the agency, cultural matters nevertheless did thrive. Congress was also supportive as the Cold War came to an end.

A Cultural Affairs Division was established within the Department of State in I938. The division was expanded after World War II, thanks to the creation of the Fulbright program and the Salzburg Seminars and the rapid spread of bi-national centers and overseas libraries. In due course, the scope of cultural diplomacy was enlarged through expanding the Fulbright program, developing other programs to send cultural specialists overseas, and funding American artists to participate in major international festivals and similar cultural events.

While these extensive programs have been heralded and often imitated by other nations, American cultural affairs always have lacked a secure locus in federal government. During the Carter Administration, the work of the Cultural Affairs Division was transferred to the USIA. During the Clinton Administration, the USIA was merged back into the State Department and a position of Under Secretary for Public Diplomacy and Public Affairs was created. That Under Secretary now oversees the Bureau of Public Affairs, the Bureau of Educational and Cultural Affairs, and the Office of International Information Programs.

\section{Structure}

To signal the importance of cultural diplomacy and elevate cultural responsibilities within the Department of State, we recommend that the portfolio of the Under Secretary be redefined and renamed as Under Secretary for Public Diplomacy and Public and Cultural Affairs. We also recommend that the Assistant Secretary who heads the Bureau of Educational and Cultural Affairs be given the rank of Ambassador-At-Large for Cultural Affairs. This position would serve to elevate U.S. representation in the international arena and better advance American interests at home and abroad. 
For these State Department programs to make their greatest contribution, their visibility must be increased, and they must be a part of thoughtful planning at the top levels of foreign policymaking. There must be consistent connections with Congress, collateral agencies in the Executive Branch, and the multitude of organizations and institutions of both the not-for-profit and the commercial sectors through which our cultural life is produced and nourished. The multiple benefits that can come from a coherent strategy of cultural diplomacy can best be maximized by elevating cultural affairs from a subordinate position within the Division of Public Affairs and Public Diplomacy.

State Department overseas missions will gain from their improved entree to the cultural policymakers of foreign countries. The State Department and the wider foreign policy community will gain from partnerships with the individuals and organizations that give such vibrancy to American cultural life. Members of Congress will benefit when constituents from the cultural sector of their individual districts find global opportunities. Private-sector businesses will gain from partnerships that enhance their overseas access. And finally, individuals and institutions within the entire cultural sector will see their work flourish from the productive collaborations, the new skills, and the fresh perspectives they can develop globally.

\section{We recommend that Congress develop a more comprehensive and integrated approach to policies affecting cultural affairs.}

\section{Rationale}

Congress currently lacks structures and mechanisms necessary to deal effectively, and on a more coordinated basis, with the range of issues, programs, and policies that affect, whether directly or indirectly, America's creative vitality and the preservation of its cultural heritage. The organization and operation of Congress do not facilitate its abilities to appreciate or utilize these creative and heritage resources to advance national goals at home and abroad. 


\section{Background}

At present, 29 authorizing and appropriating committees have jurisdiction over different aspects of the nation's cultural life. Fifteen committees in the Senate oversee federal programs affecting culture. The Health, Education, Labor and Pensions Committee is concerned with direct funding administered by federal cultural agencies such as the National Endowment for the Arts, the National Endowment for the Humanities, and the Institute for Museum and Library Services. The Energy and Natural Resources Committee oversees the historic preservation work of the National Park Service. The Foreign Relations Committee is concerned with cultural exchanges and international trade, while the Finance Committee has jurisdiction over tax policies affecting not-forprofit cultural organizations and entertainment businesses. The Judiciary Committee deliberates on antitrust policies concerning entertainment and telecommunications industries as well as on First Amendment issues. In the House of Representatives, in addition to oversight committees, the subcommittees of the Appropriations Committee direct funding levels for Executive Branch agencies that affect culture.

Different oversight and appropriations committees review the operations of scores of federal agencies, regulations, and funds that sustain and preserve American creativity and cultural heritage. Over the years, a Congressional Arts Caucus or similar working group has focused its attention on the National Endowment for the Arts; that effort drew bipartisan support from many different Committees in the House and Senate. Yet seldom does Congress have the opportunity to gain a holistic perspective of how the components of America's cultural capital are connected or how, collectively, they affect the interests of American citizens and communities.

Congress has found ways to develop better-coordinated perspectives on such disparate areas as science and technology policy, economic policy, and drug policy. In some key policy areas, Congress has been able to create new committee structures, such as the Joint Committee on Taxation and the Joint Economic Committee. In other areas, it has devised mechanisms for less formal discussion groups comprised primarily of committee

staff members. Drawing upon those diverse experiences, Congress can find solutions to the current fragmentation in addressing cultural issues. 


\section{Structure}

Congressional leaders - including party leaders, committee and subcommittee chairmen, and ranking minority members - should strive for more systemic communication and coordination of issues affecting the cultural sector. Congress might consider some of the following mechanisms:

A permanent intercommittee study group to address crosscutting issues affecting the cultural sector.

An ad hoc study group to facilitate integrated examination of cultural issues that cut across specific committee jurisdiction.

Designated committee staff charged to meet and report on crosscutting issues affecting the cultural sector.

These mechanisms would enable Congress to explore more consistently how the resources, expertise, and capacity of America's cultural sector can advance national goals and priorities. They would allow Congress to better integrate issues affecting this sector into legislative debates and decision-making in such areas as labor, education, economic development, copyright, international trade, and diplomacy.

In addition to these structural devices, Congress could take steps to inform more fully its own deliberations and to add to the information that all Americans can obtain regarding this sector. Congress could use both its own legislative support services and the capacity of executive agencies to gather information about the cultural sector by:

Asking the Congressional Research Service to conduct studies of the various policies, programs, regulations, and funding that affect the cultural sector and of the ways the sector can help advance other national interests in areas such as education, health, economic development, and foreign affairs.

Instructing federal information-gathering bureaus such as the Bureau of Labor Statistics, the Council of Economic Advisers, the Census Bureau, and other programs at Commerce, Education, and the Internal Revenue Service to expand or improve their collection and reporting activities about the cultural sector. Federal cultural agencies could also be asked to improve their research capacities. 


\section{We recommend that Congress and the President create a National Forum on Creativity and Cultural Heritage.}

\section{Rationale}

The 107th Congress and 43rd President have a unique opportunity to recognize the important role that creativity and heritage play within American society and to consider the place of culture in a global, knowledge-based economy. In the 2oth century, policies and programs concerning the arts, humanities, culture, heritage, and entertainment evolved as a disparate and unrelated lot, some more meaningful, visible, or controversial than others. In the early 2ist century, the cultural sector operates under an intertwined set of rules, regulations, and support that demands more concerted attention. The stakes and the opportunities for more coherently informing and improving the arena of cultural policy are important and substantial. Stewardship of our creative resources and cultural heritage is a natural responsibility.

\section{Background}

Currently, no such forum exists, although partial precedents and potential resources can be identified. For example, the President's Committee on the Arts and Humanities (PCAH) includes both public and private members but lacks Congressional members. Furthermore, the PCAH tends to focus on issues of concern to not-for-profit cultural organizations and public-private partnerships rather than on the entire range of creative and cultural heritage concerns. Another precedent was set in 1990 by the Independent Commission on the National Endowment for the Arts that was established by Congress with explicitly bipartisan membership appointed by the House, the Senate, and the President.

Private attention to creative, cultural, and heritage issues is also growing but tends to be episodic. For example, the American Assembly - a study group established by Dwight D. Eisenhower when he was president of Columbia University - has organized a number of productive, although intermittent, forums on specific issues such as the future of American museums, international cultural exchanges, public funding for the arts, and the arts, technology, and intellectual property. In addition, organizational and intellectual 
resources are being cultivated in the private sector through the work of academic centers and independent research institutes. Private efforts play an important role in shaping and advancing public discourse, yet all too often they focus on the narrow concerns of a specific field or entity. While they constitute resources that public policymakers can draw upon in their conduct of the nation's business, such private activities and efforts are no substitute for a National Forum established under federal auspices.

\section{Structure}

This Forum would be charged with identifying and articulating the ways in which the cultural sector can advance national and international public interests. It should include both public and private members, with public members being drawn from the legislative and the executive branches of the federal government as well as state and local governments. Private members could be drawn from the not-for-profit and commercial realm, and include artists, scholars, preservationists, and policy analysts. This National Forum could assess conditions that might merit government attention and report on the development, implementation, and outcomes of public policies that affect America's cultural capital.

The Center for Arts and Culture offers these structural recommendations for the federal government because we believe that the cultural capital of our nation must be a more central feature of federal policymaking in the 2ist century. Federal Reserve Chairman Alan Greenspan reminds us that ideas have sparked the surge in international trade and growth in productivity and wealth in recent decades. We have witnessed, he argues, "the substitution of ideas - new insights - for material bulk and brute human effort." Many states and localities have already learned how ideas, so often embodied in artistic vitality and cultural heritage, can become substantial economic assets. Some are also seeing how culture serves as a social asset, enhancing the lives of individuals and strengthening communities. These are among the subjects the Center will explore in greater detail in subsequent issue briefs. National leadership at the federal level is essential as we build upon and preserve America's cultural capital. 


\section{Center for Arts and Culture}

This publication is part of Art, Culture and the National Agenda, a multi-stage project on national policy challenges in the arts and culture. The Center for Arts and Culture is an independent think tank which seeks to broaden and deepen the national conversation on culture.

The Art, Culture and the National Agenda project, of which this report is one component, has been supported by the following foundations: The Robert Sterling Clark Foundation, the Nathan Cummings Foundation, the Thomas S. Kenan Institute for the Arts, The Open Society Institute, and the Andy Warhol Foundation for the Visual Arts. The Center for Arts and Culture receives additional funds from the Rockefeller Foundation, the Ford Foundation, the David and Lucile Packard Foundation, the Pew Charitable Trusts and the Henry Luce Foundation.

\section{BOARD OF DiRECTORS}

James Allen Smith, President

Alberta Arthurs

James Early

James Fitzpatrick

Frank Hodsoll

David Henry Hwang

John Romano

Judith O. Rubin

Marcia Sharp

Ben Wattenberg

Harold Williams

\section{RESEARCH TASK ForCe}

Milton Cummings, Jr.

Fohns Hopkins University

William Glade

University of Texas-Austin

Stanley Katz

Princeton University

Dan J. Martin

Carnegie Mellon University

\section{STAFF}

Gigi Bradford, Executive Director

Laura Becker

Allison Brugg

Keith Donohue

Sharon Kangas

Ann Galligan, Senior Associate Scholar

Glenn Wallach, Senior Associate Scholar
Clement Price

Rutgers University

Ruth Ann Stewart

Rutgers University

Margaret J. Wyszomirski, Chair

Ohio State University

As with any collective enterprise, this report represents the consensus view of the Center for Arts and Culture. It does not purport to represent the views of the Center's funders or the individual views of the members of the board, staff or research task force. 


\section{CENTER FOR ARTS AND CULTURE}

401 F Street, NW, Suite 334

Washington, DC 20001-2728

wwW.culturalpolicy-org 